\title{
An Insulin-like Growth Factor 2-Derived Self-Antigen Inducing a Regulatory Cytokine Profile after Presentation to Peripheral Blood Mononuclear Cells from DQ8 ${ }^{+}$ Type 1 Diabetic Adolescents
}

\section{Preliminary Design of a Thymus-Based Tolerogenic Self-Vaccination}

\author{
V. GEENEN, ${ }^{a}$ C. LOUIS,${ }^{a}$ H. MARTENS,${ }^{a}$ AND THE BELGIAN DIABETES \\ REGISTRY ${ }^{b}$ \\ ${ }^{a}$ University of Liège Center of Immunology (CIL), Laboratory of Neuroimmune- \\ Endocrinology and Embryology, Institute of Pathology CHU-B23, \\ B-4000 Liège-Sart Tilman, Belgium \\ ${ }^{b}$ Diabetes Research Center, Faculteit Geneeskunde en Academisch Ziekenhuis, \\ Vrije Universiteit Brussel, Laarbeeklaan 101-103, 1090 Brussels, Belgium
}

\begin{abstract}
This work aims to evaluate the potential use of insulin-like growth factor 2 (IGF-2) as the dominant thymic self-antigen precursor of the insulin family in designing a tolerogenic approach to type 1 diabetes (T1D) prevention. This evaluation was primarily based on cytokine profile driven by MHC presentation of insulin and IGF-2-derived antigens to PBMC cultures derived from $16 \mathrm{~T} 1 \mathrm{D} \mathrm{DQ8}^{+}$adolescents. Insulin $\mathrm{B9}-23$, one dominant $\beta$-cell autoantigen, and the homologous sequence B11-25 of IGF-2 display the same affinity and fully compete for binding to DQ8, a MHC-II allele conferring major genetic susceptibility to type 1 diabetes (T1D). However, compared to insulin B9-23, presentation of IGF-2 B11-25 elicits a suppressive/regulatory cytokine profile with a higher number of IL-10-secreting cells $(P<0.05)$, a much higher ratio of IL-10/IFN- $\gamma(P<0.01)$, as well as a lower number of IL4-secreting cells $(P<0.05)$. Thus, with regard to T1D prevention, administration of IGF-2-derived self-antigen(s) seems to be an efficient approach that combines both antagonism for binding to a major susceptibility MHC-II allele, as well as downstream promotion of an antigen-driven tolerogenic response.
\end{abstract}

KEYwORDs: thymus; type 1 diabetes; self-antigens; IGF-2; self-vaccination

Address for correspondence: Vincent Geenen, M.D., Ph.D., Liège University Center of Immunology (CIL), Institute of Pathology CHU-B23, B-4000 Liège-Sart Tilman, Belgium. Voice: +32 436625 50; fax: +3243662977.

vgeenen@ulg.ac.be

Ann. N.Y. Acad. Sci. 1037: 59-64 (2004). @ 2004 New York Academy of Sciences.

doi: 10.1196/annals.1337.008 


\section{INTRODUCTION}

Although the major autoantigens targeted in type 1 diabetes (T1D) have been identified, the origin of the autoimmune response directed against islet $\beta$ cells remains quite obscure. For a long time, autoimmune diseases were thought to result from a spontaneous or infection-derived breakdown of peripheral self-tolerance. Such mechanisms, however, were based on the misconception that $\beta$ cell autoantigens are sequestered from $\mathrm{T}$ cells during establishment of self-tolerance in the thymus. This concept of a topographic seclusion of pre-T cells from islet-specific autoantigens is now obsolete since the thymus parenchyma was demonstrated to be the site for transcription of genes belonging to several neuroendocrine families or encoding a variety of tissue-specific antigen precursors. ${ }^{1-8}$

A logical question derived from the elucidation of the prominent role of the thymus in self-tolerance to neuroendocrine self-principles: Could the development of $\beta$ cell autoimmunity result from a thymus dysfunction in the establishment of $\beta$ cell tolerance? That hypothesis was supported by a series of previous experimental data. Neonatal thymectomy prevents the incidence of autoimmune diabetes in the BioBreeding (BB) rat. $^{9}$ Grafts of thymus or thymic epithelium from the NOD mouse induce insulitis and sialitis in grafted recipients. ${ }^{10,11}$ Insulin (Ins) and insulin-like growth factor 1 (Igfl) gene transcripts are detected in all thymi of diabetes-prone (BBDP) and diabetes-resistant (BBDR) BB rats. While present in the thymus of BBDR rats, $I g f 2$ transcripts are contrastingly absent in the thymus of more than $80 \%$ of BBDP rats in close concordance with the incidence of diabetes in BBDP rats $(86 \%)$. This defect of Igf2 transcription is thymus-specific since Igf 2 mRNAs are detected in the liver and the brain of BBDP rats. ${ }^{12}$ In addition, the levels of INS transcripts are low in the thymus from deceased fetuses with genetic susceptibility to T1D (presence of VNTR class I alleles, see below), while they are higher in thymi from fetuses bearing protective alleles (VNTR class III alleles). ${ }^{13,14}$ Expression of Ins is also low in the thymus of NOD mice, ${ }^{15}$ while mice with thymus-restricted insulin defect develop a strong proinsulin-specific $\mathrm{T}$ cell reactivity. ${ }^{16}$ Breeding of Ins $2^{-1-}$ onto NOD mice accelerates the development of autoimmune diabetes. ${ }^{17} \mathrm{At}$ the opposite, insulitis and diabetes are considerably reduced in $I n s I^{-1-}$ congenic NOD mice. ${ }^{18}$ This may be explained by the dominance of Ins 2 expression in the murine thymus, while Ins 1 is dominantly transcribed in murine islet $B$ cells. With regard to other $\beta$ cell autoantigens, GAD67 is the dominant GAD isoform expressed in the thymus, whereas GAD65 is the autoantigen implicated in the peripheral diabetogenic autoimmunity against $\beta$ cells. ${ }^{19,20}$ An alternative splicing of IA2 occurs in the thymus and this leads to the intrathymic presentation of IA-2 antigens different from those involved in the peripheral autoimmune reaction directed to islet $\beta$ cells. ${ }^{21} \mathrm{~A}$ specific processing of preprotachykinin A (PPT-A) also takes place in thymic epithelium since only neurokinin A- but not substance $\mathrm{P}$, also derived from PPT-Ais detected in thymic epithelial cells (TECs). ${ }^{22}$ It is thus fundamental now to consider the existence of thymus-specific processing pathways, leading to the presentation of self-antigens that are not identical, but closely homologous to peripheral autoantigens. 


\section{SELF-VACCINATION AS A NOVEL AVENUE FOR T1D PREVENTION AND CURE}

Given the impossibility of modifying the genetic constitution of susceptible individuals and to act upon most of the environmental influences-except perhaps through a future anti-coxsackievirus vaccination in countries with high T1D incidence-contemporary research still privileges a regulatory approach aiming to control the specific autoimmune response oriented against $\beta$ cells, without compromising general immunity. Ideally, this autoimmune regulation could be combined with strategies aiming at the regeneration of damaged $\beta$ cells and the inhibition of the apoptotic process raised in $\beta$ cells by the autoimmune process. ${ }^{23}$ Even after transplantation of $\beta$ cells from allogenic and xenogenic donors, or $\beta$ cells issued from appropriate differentiation of stem cells, the control of the autoimmune memory against islet $\beta$ cells is an absolute requirement both for prevention and cure of T1D.

According to the recent knowledge gained in T1D pathophysiology and in the central role of the thymus for establishment of islet $\beta$ cell self-tolerance, such regulation of the autoimmune process could be obtained by (re)programming $\beta$ cell tolerance through the potent tolerogenic properties of the thymus, in particular the thymic repertoire of neuroendocrine self-antigen precursors. In this perspective, the

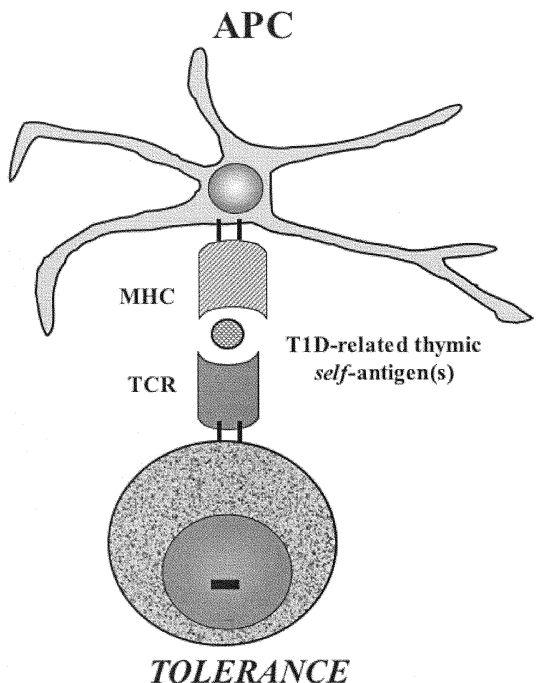

Clonal deletion, anergy

Treg generation

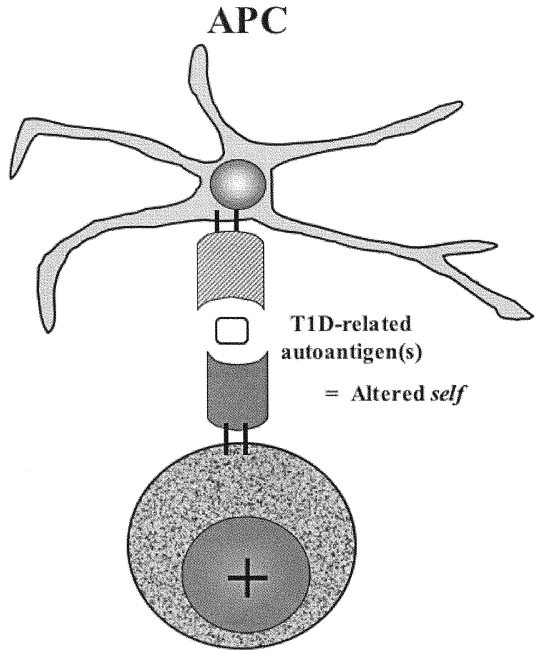

AUTOIMMUNITY

Activation of self-reactive $T$ cells

Induction of memory $T$ cells

FIGURE 1. Self-vaccination as a novel strategy for prevention and cure of autoimmune diseases. The basic principle relies on the difference of immune responses elicited by peripheral autoantigens and homologous self-antigens predominantly expressed in the thymus. The self-vaccination combines antagonism for binding to MHC presentation "pocket" and a regulatory/tolerogenic response downstream of the self-antigen presentation. 
profile of cytokine secretion was analyzed after presentation of the sequence Insulin B9-23, a major T1D autoantigen, and the sequence B11-25 derived from IGF-2, the dominant self-antigen of the insulin family expressed in the thymus. This study was performed in cultures of peripheral blood mononuclear cells (PBMCs) derived from DQ8-positive T1D adolescents. First, in collaboration with Kai Wücherpfennig, Insulin B9-23 and IGF-2 B11-25 were shown to have the same affinity and to compete for binding to DQ8. Then, using the ELISPOT methodology, DQ8 presentation of IGF-2 B11-25 was shown to induce a regulatory profile ( $\uparrow$ IL-10, $\uparrow$ IL-10/IFN- $\gamma, \downarrow$ IL-4), significantly different from the profile induced by Insulin B9-23. Such a regulatory profile could derive from the behavior of IGF-2 B11-25 acting as a natural altered peptide ligand for insulin-reactive $\mathrm{CD} 4^{+} \mathrm{T}$ cells, or from the recruitment and activation of IGF-2-specific Treg. Thus, in contrast with the absence of any tolerogenic properties for insulin, ${ }^{24-27}$ IGF-2 and derived epitopes seem to constitute a very appropriate choice for a novel type of immunotherapy/vaccine associating both a competition at the level of MHC presentation and a regulatory immune response downstream (FIG. 1). Preclinical studies with administration of IGF-2 B11-25 to animal models of T1D have not yet been performed, but it is now evident that the use of such experimental models cannot determine the efficiency of immunointervention in T1D patients. ${ }^{28}$ The benefit of an association of these self-peptides with in vitroexpanded antigen-specific Treg should also be evaluated in the near future. ${ }^{29,30}$

\section{ACKNOWLEDGMENTS}

Vincent Geenen is Research Director of the Belgian NFSR, Director of the Liège Center of Immunology, Professor of Embryology at Liège University, and Coordinator of the Euro-Thymaide FP6 Integrated Project. These studies are supported by Fondation Leon Fredericq (Liège Medical School), by NFSR, by Fondation Vaugrenier for Tolerance Research (Geneva), by the European Association for the Study of Diabetes (EASD, Düsseldorf), and by the European Commission, R\&D Directorate (Euro-Thymaide IP contract LSHB-CT-2003-503410).

\section{REFERENCES}

1. Geenen, V., F. Robert, H. Martens, et al. 1992. The thymic education of developing $\mathrm{T}$ cells in neuroendocrine self-principles. J. Endocrinol. Invest. 15: 621-629.

2. Robert, F., H. Martens, N. Cormann, et al. 1992 The recognition of hypothalamoneurohypophysial functions by developing T cells. Dev. Immunol. 2: 131-140.

3. Joliceur, C., D. Hanahan \& K.M. Smith. 1994. T-cell tolerance toward a transgenic beta-cell antigen and transcription of endogenous genes in the thymus. Proc. Natl. Acad. Sci. USA 91: 6707-6711.

4. Geenen, V. 1995. La Communication Cryptocrine Intrathymique et la Tolérance Centrale au Soi Neuroendocrine. Professoral thesis, University of Liège.

5. Martens, H., B. Goxe \& V. Geenen. 1996. The thymic repertoire of neuroendocrine self-peptides: physiological implications in T-cell life and death. Immunol. Today 17: $312-319$.

6. Vanneste, Y., A. Ntodou-Thome, E. Vandersmissen, et al. 1997. Identification of neurotensin-related peptides in human thymic epithelial cell membrane and relationship with major histocompatibility class I molecules. J. Neuroimmunol. 76: 161166. 
7. Derbinski, J., A. Schulte, B. Kyewsky \& L. Klein. 2001. Promiscuous gene expression in medullary thymic epithelial cells mirrors the peripheral self. Nat. Immunol. 2: 1032-1039.

8. Geenen, V., F. Brilot, I. Hansenne, et al. 2004. Thymus and T cells. In Encyclopedia of Neuroscience on CD-ROM, 3rd edit. G. Adelman \& B.H. Smith, Eds. Elsevier. New York. ISBN 0-444-51432-5.

9. Like, A.A., E. Kislaukis, R.M. Williams \& A.A. Rossini. 1982. Neonatal thymectomy prevents spontaneous diabetes mellitus in the BB:W rat. Science 216: 644646.

10. Georgiou, H.M. \& T.E. Mandel. 1995. Induction of insulitis in athymic (nude) mice. The effect of NOD thymus and pancreas transplantation. Diabetes 44: 49-59.

11. Thomas-Vaslin, V., D. Damotte, M. Coltey, et al. 1997. Abnormal T-cell selection on NOD thymic epithelium is sufficient to induce autoimmune manifestations in C57BL/6 athymic nude mice. Proc. Natl. Acad. Sci. USA 94: 4598-4603.

12. Kecha-Kamoun, O., I. Achour, H. Martens, et al. 2001. Thymic expression of insulin-related genes in an animal model of type 1 diabetes. Diabetes/Metab. Res. Rev. 17: $146-152$.

13. Vafiadis, P., S.T. BennetT, J.A. TodD, et al. 1997. Insulin expression in human thymus is modulated by INS VNTR alleles at the IDDM2 locus. Nat. Genet. 15: 289292.

14. Pugliese, A., M. Zeller, A. Fernandez, JR., et al. 1997. The insulin gene is transcribed in the human thymus and transcription levels correlate with allelic variation at the INS VNTR-IDDM2 susceptibility locus for type 1 diabetes. Nat. Genet. 15: 293-297.

15. Brimnes, M.K., T. Jensen, T.N. Jorgensen, et al. 2002. Low expression of insulin in the thymus of non-obese diabetic mice. J. Autoimmun. 19: 203-213.

16. Chentoufi, A.A. \& C. Polychronakos. 2002. Insulin expression levels in the thymus modulate insulin-specific autoreactive T-cell tolerance: the mechanism by which the IDDM2 locus may predispose to diabetes. Diabetes 51: 1383-1390.

17. Thebault-Baumont, K., D. Dubois-Laforgue, P. Krief, et al. 2003. Acceleration of type 1 diabetes in proinsulin 2 deficient mice. J. Clin. Invest. 111: 851-857.

18. Moriyama, H., N. Abiru, J. Paronen, et al. 2003. Evidence for a primary islet autoantigen (preproinsulin 1) for insulitis and diabetes in the nonobese diabetic mouse. Proc. Natl. Acad. Sci. USA 100: 10376-10381.

19. Kaufman, D.L., M.C. Clare-Salzler, J. Tian, et al. 1993. Spontaneous loss of T-cell tolerance to glutamic acid decarboxylase in murine insulin-dependent diabetes. Nature 366: 69-72.

20. Gotter, J., B. Brors, M. Hergenhahn \& B. Kyewski. 2004. Medullary epithelial cells of the human thymus express a highly diverse selection of tissue-specific genes colocalized in chromosomal clusters. J. Exp. Med. 199: 155-166.

21. Diez, J., Y. Park, M. Zeller, et al. Differential splicing of the IA-2 mRNA in pancreas and lymphoid organs as a permissive genetic mechanism for autoimmunity against the IA-2 type 1 diabetes autoantigen. Diabetes 50: 895-900.

22. ERICsSon, A., V. GEenen, F. Robert, et al. 1990. Expression of preprotachykinin-A and neuropeptide-Y messenger RNA in the thymus. Mol. Endocr. 4: 1211-1218.

23. EIZIRIK, D.L. \& T. MANDRUP-PAulSEN. 2001. A choice of death: the signal-transduction of immune-mediated beta-cell apoptosis. Diabetologia 44: 2115-2133.

24. Chaillous, L., H. Lefevre, C. Thivolet, et al. 2000. Oral insulin administration and residual beta-cell function in recent-onset type 1 diabetes: a multicentre randomized controlled trial. Diabetes Insulin Oral Group. Lancet 356: 545-549.

25. Pozzilli, P., D. Pitocco, N. Visalli, et al. 2000. No effect of oral insulin on residual beta-cell function in recent-onset type 1 diabetes. Diabetologia 43: 1000-1004.

26. DPT-Type 1 Diabetes STUdy Group. 2002. Effects of insulin in relatives of patients with type 1 diabetes. N. Engl. J. Med. 346: 1685-1691.

27. Gottlieb, P.A. \& G.S. Eisenbarth. 2002. Insulin-specific tolerance in diabetes. Clin. Immunol. 102: 2-11.

28. AtKinson, M.A. \& E.H. Leiter. 1999. The NOD mouse model of type 1 diabetes: as good as it gets? Nat. Med. 5: 601-604. 
29. Tarbell, K.V., S. YamazaKi, K. Olson, et al. 2004. CD25+ CD4+ T cells expanded with dendritic cells presenting a single autoantigenic peptide, suppress autoimmune diabetes. J. Exp. Med. 199: 1467-1477.

30. TANG, Q., K.J. HENRIKSEN, M. BI, et al. 2004. In vitro-expanded antigen-specific regulatory T cells suppress autoimmune diabetes. J. Exp. Med. 199: 1455-1465. 